\title{
Busca por Felicidade e Sentido de Vida na Sociedade de Consumo no Olhar da Logoterapia ${ }^{1}$
}

\author{
Search for Happiness and Sense of Life in the Consumer Society in the Look of Logotherapy
}

Adrielly Portes Machado Ramos ${ }^{\dagger *}$, Fátima Niemeyer da Rocha

Como citar esse artigo. Ramos, A.P.M., Rocha, F.N. Busca por Felicidade e Sentido de Vida na Sociedade de Consumono Olharda Logoterapia. Revista Mosaico. 2018 Jan./Jun.; 09 (1): 10-18.

\begin{abstract}
Resumo
O trabalho tem o objetivo de discutir a situação do homem contemporâneo frente aos investimentos da sociedade hipermoderna, no que se refere ao consumo exacerbado (hiperconsumismo) e às ilusórias sensações de felicidade, prazer e sentido de vida provenientes dessa prática. Problematizam-se as razões que levam o homem hipermoderno às aquisições e a impregnar as coisas de sentido na busca pela felicidade, ações que o tem conduzido a vivenciar a neurose de massa da atualidade - o vácuo existencial. Dessa forma, foram analisadas a constituição da subjetividade dos indivíduos e a sua saúde emocional frente a essa realidade consumista. Através da logoterapia, doutrina criada por Viktor Emil Frankl, e de seus conceitos gerais, buscou-se compreender a derivação do prazer e da felicidade verdadeiros, provenientes de um sentido genuíno na vida, como também elucidar a propiciação de uma existência saudável a partir do exercício da responsabilidade e da liberdade frente às escolhas da vida. A logoterapia, portanto, tem muito a contribuir como psicoterapia e, também, como complemento às demais psicoterapias no que tange ao encontro do homem hipermoderno com o sentido, a felicidade e o prazer, pois, ao considerar a inserção do logos (sentido), consequentemente considera a existência e a reflexão sobre a mesma, tornando possível a superação da falta de sentido.

Palavras-Chave: Sociedade hipermoderna, Felicidade, Sentido de vida, Logoterapia.
\end{abstract}

\begin{abstract}
This work aims to discuss the situation of contemporary man, front of the investments of hypermodern society with regard to the exaggerated consumption (hyperconsumption) and illusory sensations of happiness, pleasure and meaning of life from this practice. It problematizes the reasons that lead the hypermodern man to the acquisition and to imbue the meaning of things in the search for happiness, actions that have led him to experience the mass neurosis of our time - the existential vacuum. Thus, the constitution of subjectivity of the individuals and their emotional health front this consumerist reality was analyzed. Through logotherapy, doctrine created by Viktor Emil Frankl, and its general concepts, the understanding of the derivation of pleasure and true happiness, from a genuine meaning in life was sought, as well as the elucidation of the propitiation of a healthy existence from exercise of responsibility and freedom in the face of life choices. Logotherapy, therefore, has much to contribute as psychotherapy and also as a complement to other psychotherapies regarding the meeting of hypermodern man with meaning, happiness and pleasure, because, when considering the insertion of logos (meaning) consequently considers the existence and reflection on it, making it possible to overcome the lack of meaning.

Keywords:: Hypermodern society, Happiness, Meaning of life, Logotherapy.
\end{abstract}

\section{Introdução}

Na sociedade contemporânea homens e mulheres têm sido compelidos, cada vez mais, a consumirem. Isso ocorre devido ao enorme apelo midiático e, mais que isso, às propostas de satisfação e felicidade imediatas. Com essa promessa, a busca pela felicidade e prazer nas coisas se tornou a compulsão dessa geração, o sentido da vida das pessoas. No entanto, a materialidade nunca pôde e nunca poderá oferecer a felicidade tão almejada, pois, antes de tudo, a existência humana carece de sentido para se achar completa. Levanta-se a tese, então, de que o consumismo se manifesta em sua forma mais intensa nos indivíduos assolados por problemas existenciais crônicos, surgindo como mecanismo substitutivo para o preenchimento de uma falta, um vazio interior.

O estudo objetivou, dessa forma, a compreensão do surgimento da expectativa de felicidade e de prazer nos objetos que tão fortemente consolida-se na Sociedade Hipermoderna - termo cunhado por Gilles Lipovetsky - e que tem provocado problemas existenciais dos mais diversos. Assim como, através da logoterapia de Viktor Emil Frankl, entender a natureza desses problemas, suas causas e possíveis respostas que levem a uma existência

Afiliação dos autores: † Psicóloga, Graduada pela Universidade Severino Sombra, Vassouras, RJ, Brasil.

\$ Doutora em Psicologia, Professora do Curso de Psicologia da Universidade de Vassouras, Vassouras, RJ, Brasil.

Email para correspondência: fatimaniemeyer@hotmail.com

O presente texto tem como base um Trabalho de Conclusão de Curso apresentado ao Curso de Psicologia da USS. 
saudável.

Muitos estudiosos têm realizado uma análise da sociedade contemporânea no que tange a sua implicação à falta de sentido vigente, à experimentação do vazio existencial. Lipovetsky (2007), ao apresentar o conceito de sociedade hipermoderna, destaca a relação efêmera e hedonista do homem com o consumo, que o leva ao consumo excessivo, sempre em busca de novas experiências que o satisfaçam. Também Bauman (2009) discute as características da sociedade contemporânea, utilizando o termo "liquidez" para se referir à forma de viver do homem pós-moderno, remetendo diretamente à falta de solidez nas relações e nos valores, justamente relacionados ao consumo intenso e a evolução tecnológica. Uma metáfora referente à instabilidade do ser, onde nada permanece por muito tempo, pois está sempre mudando. E, para Frankl (1990), embora a sociedade de consumo esteja constantemente criando necessidades, o desejo de encontrar sentido permanece sem ser satisfeito, pois ocorre sua terceirização, quando ele deveria ser primário na vida do ser humano.

A substituição do sentido pelo imediatismo das sensações, nada mais é do que um autoengano, pois quanto mais se adquire e se granjeia, mais o indivíduo encontra-se vazio e sem um sentido para viver. Nessa perspectiva, surge a possibilidade do desenvolvimento de patologias, tendo em vista as repercussões negativas dos investimentos que o ser humano tem feito em coisas, e não nele mesmo. A forma irreflexiva de agir, apenas reproduzindo as ações da massa, torna preocupante o futuro da sociedade, tornando necessário pensar a possibilidade de uma existência mais consciente, responsável e livre diante das ofertas do mundo, o que foi feito através da logoterapia.

Para tanto, discute-se as implicações da sociedade de hiperconsumo no que se refere à falta de sentido e a experimentação do vazio existencial, buscando fomentar uma explanação psicológica à luz da logoterapia. Aborda-se os principais conceitos utilizados por Frankl para explicar a busca do prazer e da felicidade. E, pensando as implicações da sociedade hipermoderna, aponta-se para possíveis alternativas, a partir das contribuições da logoterapia, para um existir saudável e pleno de sentido.

\section{Sociedade hipermoderna e a ilusão da felicidade pelo consumo: um convite à falta de sentido}

A sociedade de consumo pode ser perfeitamente enlaçada a uma das passagens da Odisseia, na qual Homero (2002) narra o naufrágio de Ulisses na costa da ilha Ogígia, pertencente à ninfa Calipso. Esta o acolhe em sua morada e por ele se apaixona. Calipso passava os dias a tecer e a fiar e insistia em seduzi-lo, oferecendothe prazeres eternos, inclusive a imortalidade, se aceitasse ali permanecer com ela. O lugar é descrito por Homero como um paraíso, florido e arborizado, de lindas paisagens, onde os homens virtuosos descansam, se divertem e vivem de infinitos deleites. Ali também se encontrava o rio Lethe - cujo significado grego é "esquecimento", "ocultação" -, e todo aquele que bebesse das águas do rio esqueceria tudo que havia vivido até então.

Tendo em vista as características da contemporaneidade, a Ilha de Ogígia serve para ilustrar a sociedade atual, que propicia uma inimaginável gama de objetos e prazeres e na qual se encontram o esquecimento e a alienação em relação às nossas próprias vidas. Na "Ogígia contemporânea", as pessoas mostram-se irreflexivas, dominadas pelos modos de ser e pensar da massa, conferindo às suas vidas crenças e valores sem sequer ponderar as escolhas feitas. Essa forma irreflexiva de viver desvia os verdadeiros desejos dos indivíduos, levando-os a negação de suas vontades e sentimentos. É o que os conduz ao consumo precipitado, que desconsidera qualquer necessidade real, apenas a volição imediata do prazer, independente dos meios de adquiri-lo. (SOUZA, 2011)

Estas considerações a respeito da sociedade contemporânearepercutemnas perspectivas sociológicas e filosóficas de Bauman (2009), Baudrillard (1991; 1993) e Lipovetsky (2007), entre outros, os quais se interessam por explorar a relação entre consumo e felicidade, equação central para a compreensão que trazem da sociedade atual.

A "sociedade de consumo" caracteriza-se, antes de tudo, pelo desejo socialmente expandido da aquisição "do supérfluo", do excedente. Do mesmo modo, se estrutura pela marca da insaciabilidade, da constante insatisfação, onde uma necessidade preliminarmente satisfeita gera quase automaticamente outra, num ciclo que não se esgota, onde o final do ato consumista é o próprio desejo de consumo. (CAMPBELL, 2001)

A forma como se atrelou felicidade ao ato de consumir começa, de alguma forma, numa estratégia capitalista, onde se insere a ideia de que por meio da obtenção de bens materiais é que o indivíduo encontra a felicidade. Assim, os objetos passam a representar uma felicidade materializada.

Refletindo sobre a cultura do consumo e suas interferências na vida humana, inserida na sociedade que denominou de "líquido-moderna", Bauman (2009) busca compreender os referenciais valorativos que justificam a procura da felicidade no mundo contemporâneo e o efeito que estes produzem na identidade dos sujeitos e em seus relacionamentos sociais. Compara a vida a uma obra de arte, que muda, se atualiza e ganha novos significados continuamente. $\mathrm{O}$ artista da vida, por sua vez, sempre tenta criar uma obra satisfatória, revelando a sua permanente busca pela felicidade.

Lipovetsky (2007) também reforça a concepção 
de felicidade como um ditame da sociedade de consumo. Discute as práticas de consumo na sociedade contemporânea - a sociedade do Hiperconsumo, onde predomina uma cultura efêmera e hedonista, denominada por ele de "civilização do desejo", iniciada na segunda metade do século XX, e norteada pela propagação do capitalismo -, e as experiências subjetivas que geram, salientando que os indivíduos buscam satisfações individuais. Nessa 'civilização do desejo' o interesse se volta ao que se presentifica, às experiências do agora. E, nesse sentido, a tentativa de encontrar o derradeiro valor da sociedade de consumo - a felicidade - pode se expressar na busca pelo bem-estar emocional.

Refletindo acerca da felicidade na contemporaneidade, Lipovetsky (2007) atribuiu os investimentos do mercado consumista à herança mitológica do deus Dionísio, o distribuidor de alegrias em abundância, que instigava os homens à obtenção do prazer pleno. Esse ethos de alegria teria sido redescoberto pelo homem atual, preponderando na cultura presente, onde se manifesta o ímpeto pelas sensações imediatas, sejam no corpo ou nos sentidos oferecidos pelos objetos. A felicidade, desse modo, deve se realizar no presente, tem que ser satisfeita imediatamente, mediada por guias e métodos para viver melhor, por conselhos de saúde e de boa forma apresentados na televisão e nos jornais, por promessas de plenitude apontadas pelos gurus etc.

Os questionamentos de Lipovetsky (2007) acerca da sociedade de hiperconsumo advêm da percepção de que a projeção de felicidade nos objetos é capaz de destruir as relações e vínculos sociais dos indivíduos. Ele enfatiza a diferença entre o Ter e o Ser na equivocada concepção de felicidade investida na materialidade, tornando o homem vítima do consumo, evidenciando sua alienação.

Bauman (2009), a respeito da felicidade na sociedade de consumo, corrobora com o pensamento de Lipovetsky (2007) admitindo que a felicidade é o valor supremo desejado incessantemente pelos indivíduos. E enfatiza que recursos necessários à vida, como amor, amizade, prazeres e a própria felicidade, não podem ser, de forma alguma, comercializados. Todavia, é o que tem ocorrido, com a tentativa de venda dos valores imensuráveis que invade o humano como crença, mas que, na realidade, é puramente uma estratégia de marketing. Deste modo, Bauman (2009) destaca que, na sociedade vigente, é por meio da aquisição dos objetos que se alcança o estado de felicidade. Contudo, tal estado não perdura e a procura por sua manutenção não cessa, sendo no esgotamento dos contentamentos que se condiciona a esperança de ser feliz.

Outro aspecto apontado por Bauman (2009), no que se refere à busca pela felicidade, é a relação que esta encontra com a identidade dos sujeitos. Ele aponta para uma agregação de valores que despersonaliza as pessoas, pois se trata da formação de uma identidade líquida, constituída momentaneamente na busca do encontro com o seu eu. Essa identidade se faz na aquisição das mercadorias, se estabelecendo na substituição acelerada do velho pelo novo. As relações sociais, por sua vez, também estão submetidas aos bens de consumo, isto é, aos objetos e ao sentimento de pertencimento social alcançado na própria identificação do eu com as tendências de estilo.

Ainda sobre as relações entre felicidade e consumo, Campbell (2001) afirma que o pensamento dos consumidores se fundamenta numa estrutura hedonista. $\mathrm{O}$ hedonismo moderno estaria fundeado em emoções controladas pela imaginação, numa desordem "visual" das disposições de prazeres ofertados pelos objetos e mercadorias. A cultura hedonista se apoia no gozo do prazer nos atos de consumo, proporcionado pelos sentidos. O desejo é precípuo no consumismo moderno, pois na busca interminável da felicidade nas mercadorias é provocado o desejo pelo novo. Dessa forma, a expectativa da felicidade, dos sonhos, se liga aos sentimentos sociais, pois na medida em que os objetos se tornam obsoletos, provocam a frustração e o constrangimento.

Baudrillard (1993) também reforça a ideia de que a felicidade se define como o status quo da sociedade de consumo, comparando a felicidade à salvação da alma, como um valor a ser atingido. Em "A Sociedade de Consumo", analisou a relação entre felicidade, propaganda e consumo, indagando sobre o que pode trazer felicidade no mundo contemporâneo. Afirma que a felicidade estaria incutida no ato de consumir, no que tange às satisfações e realizações últimas na existência humana.

Além disso, Baudrillard (1991) também focaliza a associação entre consumo e felicidade quando a cultura industrial mostra, em suas produções (novelas, filmes, propagandas, videoclipes, entre outras), a personificação da realização existencial na aquisição de mercadorias. A satisfação plena encontra-se ajustada ao Ter, passando a ser também espiritualmente necessário. $\mathrm{O}$ jogo de sedução advindo dessa cultura tenta envolver o consumidor, tornando-o seu refém. Cria novas necessidades, transforma as novidades tecnológicas em indispensáveis, independentemente do gosto do consumidor, desviando o seu poder de demandar os produtos do mercado.

$\mathrm{Na}$ sociedade de consumo o indivíduo considera que, cedendo à oferta midiática, interpretada por uma personagem fictícia transmissora de felicidade, também a alcançará. No entanto, quem consome esperando conquistar felicidade não poderá, de fato, encontrá-la, pois emaranha-se num vazio que só um outro "novo" poderá preencher. Mesmo que o indivíduo possa granjear tudo aquilo que considera substancial para a sua satisfação, os problemas existenciais persistirão, mantendo-o ainda distante da felicidade que deseja. 


\section{(BAUDRILLARD, 1991)}

O poder de compra mostra-se, portanto, como um artifício supridor de frustrações e carências, sendo o consumo "[...] uma forma de consolo, que funciona também como um agente de experiências emocionais que valem por si mesmas". (LIPOVETSKY, 2007, p. 61) A tão almejada felicidade na sociedade de hiperconsumo é também comparada à salvação - relacionada à fuga dos problemas e frustrações do dia a dia -, procurada por todos, pois "toda a sociedade se mobiliza em torno do projeto de arranjar um cotidiano confortável e fácil, sinônimo de felicidade". (LIPOVETSKY, 2007, p. 35)

Dessa forma, o homem contemporâneo é compelido a acreditar no consumo como forma de concretização da felicidade e de suas satisfações. Perdese, porém, nos sentimentos momentâneos que ofuscam a posterioridade dos desejos que serão criados e precisarão ser satisfeitos. Nesse esforço por satisfazer-se, mas não conseguir saciar-se, se culpa, ficando ainda mais infeliz, embora na sutileza do consumo encontre o deleite de que precisa para amenizar, ao menos temporariamente, seus tormentos existenciais. Assim, o cenário atual remete novamente à Ilha de Ogígia, o reino do esquecimento, de busca por prazeres contínuos e ininterruptos, pois estamos continuamente envolvidos nas perpétuas possibilidades de satisfação, sempre buscando nos fartar dos desejos e dos objetos que satisfaçam/preencham o vazio existencial evidente. (LIPOVETSKY, 2007)

Assim, de acordo com Lipovetsky (2007), no que diz respeito à sociedade de hiperconsumo, o sentimento de felicidade paradoxal manifesta-se na abundância do consumo e na exacerbante carência, na insatisfação e no vazio. Esse novo ethos é o que tem provocado no indivíduo hipermoderno o isolamento e a insegurança, tornando-o mais propenso a frustrações e a insatisfação existencial.

Nesse cenário, indaga-se quanto a possibilidade de resolução do mal-estar originado no vínculo entre felicidade e satisfação pessoal nessa realidade hiperconsumista, mas também e, principalmente, de percepção da real responsabilidade por esse mal-estar, no olhar de Frankl.

\section{Busca do prazer e da felicidade: uma discussão no horizonte da Logoterapia}

Para a Logoterapia o sentido é a força motriz da existência. O próprio termo logos, que constitui a palavra, é de origem grega e significa sentido. A essência da felicidade, definida pela Logoterapia, remete à ideia de que nada na vivência humana pode ser compreendido como um meio por si só, mas como resultado de uma razão maior na existência, uma consequência dessa razão, e não uma causa. (FRANKL, 1990) Dessa forma, a logoterapia é entendida como o tratamento através do sentido. (RODRIGUES, 1991)

A Logoterapia está apoiada no tripé fenomenológico-existencial-humanista. (LUKAS, 1989) Frankl (1984) caracterizou a busca por um sentido como a motivação primária na vida de cada indivíduo, que chamou de Vontade de Sentido: uma manifestação da autotranscedência da existência, pois o ser humano se torna completamente ele mesmo apenas quando se dedica a algo maior do que ele mesmo, esquecendo de si e se colocando a serviço de uma causa ou do amor a uma outra pessoa. É "como o olho, que só pode cumprir sua função de ver o mundo enquanto não vê a si próprio". (FRANKL, 1991, p. 18)

Entendendo a existência humana como "auto transcendente", Frankl enfatiza que o ser humano "se realiza, não se preocupando com o realizar-se, mas esquecendo a si mesmo e dando-se, descuidando de si e concentrando seus pensamentos para além de si". (FRANKL, 2005, p. 29) A própria palavra Existir, originária do latim ek-sistere, refere-se a "sair de si". Auto transcender, dessa forma, se daria na capacidade do ser humano de sobrepor-se a si, às próprias necessidades, se superando e encontrando, assim, o sentido. A vontade de sentido, então, é direcionada a encontrar esse sentido, baseada na auto transcendência.

ALogoterapia rejeita a noção de "autorrealização" no que diz respeito a buscas únicas e derradeiras do ser humano por outras motivações que não sejam, fundamentalmente, o sentido. Frankl (1988) argumenta que a preocupação em excesso em autorrealizar-se leva o ser humano a frustração de sua vontade de sentido, atribuindo a si mesmo a função de alvo maior de suas inquietações, ao falhar nessa busca por sentido. A autorrealização é o resultado da realização de um sentido no mundo.

A respeito da "hierarquia das necessidades" de Abraham Maslow, Frankl alega ser pouco efetiva a forma como o autor organizou as necessidades em questão, visto que para a Logoterapia o que tem relevância é o deparar-se com o sentido. Nessa perspectiva, não se trata de ter que haver uma reorganização das necessidades, mas de o próprio sujeito discernir qual delas trará sentido ou será um objetivo em sua realização. Para a Logoterapia, a categorização que Maslow elabora "não explica o fato de que, quando as mais baixas não são satisfeitas, uma necessidade mais elevada, o desejo de sentido, pode transformar-se na mais urgente de todas". (FRANKL, 2005, p. 27)

$\mathrm{Na}$ ordenação hierárquica de Maslow as necessidades fisiológicas estão na base da pirâmide e disso depreende-se que quaisquer outras necessidades não poderiam ser satisfeitas até que as primárias fossem supridas. Frankl ressalta que, nessa visão, o homem jamais seria compelido a pensar em um sentido para a sua vida; no entanto, observou que mesmo nas situações mais extremas, de desgraças e calamidades, os 
indivíduos podem sim pensar em um sentido. E ressalta: "uma vez que tanto a satisfação como a frustração das necessidades mais baixas podem provocar o homem a procura de um sentido, devemos concluir que a necessidade de um sentido é independente das outras necessidades". (FRANKL, 2005, p. 27)

A felicidade, por sua vez, também carece de um sentido para ser, e isso quer dizer que, "com uma razão para ser feliz, a felicidade surge automaticamente como efeito colateral". (PEREIRA, 2007, p. 129) Diante disso, aquele que persegue fixamente ideias sobre "felicidade", "prazer" ou "poder" ou que tem outro objetivo que supere a realização de um sentido primeiro, se afasta ainda mais de alcançar tal objetivo. Buscar diretamente uma felicidade integral é visto pela Logoterapia como, possivelmente, uma motivação patogênica, que Frank1 compreende a partir do que denominou "princípio auto anulativo", ou seja, quanto mais se persegue uma ideia como suficiente e completa, em substituição ao vivenciar o sentido propriamente dito, mais ainda o indivíduo se afasta do que a priore lhe motivava.

A máxima de Frankl de que "Não se deve buscar a felicidade" salienta, exatamente, que se existir uma razão para a felicidade esta será uma decorrência espontânea e automática, não necessitando persegui-la. Portanto, a felicidade não pode servir de objeto motivacional, visto que, passando a ser um instrumento de distração, coloca fora de alcance a razão para ser feliz, afastando o sujeito da felicidade real. (FRANKL, 1988, p. 33)

Segundo a Logoterapia, a sociedade contemporânea, no entanto, tenta, a todo custo, distorcer a ideia de que a necessidade de sentido é a necessidade primeira a ser satisfeita, a busca intrínseca e deveras necessária para a existência humana, principalmente através do consumo, que pelo marketing procura atribuir aos produtos um sentido, uma razão, um motivo para aquele objeto ser adquirido. (LAZZARI JUNIOR, 2013) A sociedade procura satisfazer todas as necessidades humanas pelo consumo e visa, até mesmo, "criar necessidades que possam depois ser por ela satisfeitas. Apenas a necessidade mais humana de todas, a necessidade de sentido, é frustrada pela sociedade". (FRANKL, 2011, p. 101)

Diante da observação de que o prazer é uma das principais prioridades do ser humano, compreendese a frustração existencial que vigora dos dias atuais. (LAZZARI JUNIOR, 2013) Como algo líquido, o prazer prometido através da aquisição, se esvai e toma o seu lugar um descontentamento frente ao objeto, até então desejado, e diante de si mesmo. (LIPOVETSKY, 2007) Da mesma forma como ocorre com a felicidade, não se pode buscar o prazer, porque ele também é uma consequência. Enquanto o motivo da existência for egocêntrico, buscado no benefício próprio e colocado nas necessidades como metas, haverá sempre a frustração e o vazio como resultado. (SILVA, 2012)
"Nós chamamos de vontade de sentido simplesmente àquilo que é frustrado no homem sempre que ele é tomado pelo sentimento de falta de sentido e de vazio". (FRANKL, 1991, p. 25) É a vontade de sentido que orienta a superação de tais frustrações quando o indivíduo se entrega à sua procura e encontra, não "um", mas "o" sentido no que realiza, não nele mesmo, mas fora dele, num encontro genuíno com o outro. (MOREIRA e HOLANDA, 2010)

O esforço humano em buscar a felicidade, dessa forma, acaba por ser inútil no olhar logoterapêutico. Sobre essa busca persistente, Kierkegaard metaforizou: "a porta da felicidade abre-se 'para fora', ou seja, ela fecha-se exatamente para quem tenta empurrá-la para dentro". (MOREIRA e HOLANDA, 2010) Também Frankl (2013), sobre essa expectativa de felicidade, utilizou o recurso metafórico do bumerangue para explicar que este só retorna a quem o lançou se não tiver encontrado um alvo. E, portanto, não seria preciso conduta outra que diferisse de somente esperar a chegada da felicidade, pois quando ela se depara com um sentido, ela fica.

Assim, em sua teoria Frankl (2013) deixa claro que os ideais que o ser humano coloca como prioridade, tais como o prazer e a felicidade, nada mais são do que efeitos colaterais de uma orientação ontológica que dá real significado a sua vida. A discrepância, então, entre o indivíduo que se auto realiza e o que auto transcende está, justamente, na aspiração das necessidades: um voltado à forma solipsista de viver e o outro voltado ao mundo, para o mundo/o outro - um sem razão ou motivos, outro inundado de sentido. (PEREIRA, 2007)

É preciso, porém, explorar as questões do vazio existencial e da falta de sentido, provenientes da conduta equivocada acerca da busca por prazer e felicidade e, mais que isso, esclarecer, na visão da Logoterapia, como é possível alcançar uma existência saudável e com sentido na sociedade hipermoderna.

\section{Contribuições da logoterapia para uma existência saudável na sociedade hipermoderna}

Lipovetsky (2007) atribuiu à sociedade hipermoderna uma característica de hiperconsumismo, para designar o consumo exacerbado, voltado à procura da felicidade na materialidade, "custe o que custar". Diante disso, a Logoterapia destaca a felicidade como efeito, e não como fundamento da existência, não podendo se materializar naquilo que a sociedade oferece. (MATOS, 2012)

A dinâmica histórica evidencia a construção desse consumismo hiperbólico, que se efetiva, então, na sociedade atual. O imediatismo das sensações, intrínseco nos atos consumistas, mobiliza o indivíduo a preencher imediatamente o que lhe falta; no entanto, 
este se percebe cada vez mais vazio e insatisfeito, já que tais sensações se esvaem com rapidez, levando-o a um círculo vicioso hiperconsumista. (MATOS, 2012)

Sobre essa característica contemporânea, Frank1 (1978, p. 57) afirmaria que "há muito dinheiro, não há objetivo de vida. As pessoas têm de que viver, não para que viver", ratificando que o consumo é apenas a forma que o homem contemporâneo encontrou de suprir superficialmente a falta de um sentido para a sua vida. (ZAMULAK, 2015) Ao não encontrar um propósito maior em sua existência, se torna uma marionete da sociedade, "um joguete nas mãos de chefes e sedutores autoritários e totalitários". (FRANKL, 1986, p. 26)

A resignação humana diante das contingências sociais gerou uma fuga das responsabilidades e um temor em vivenciar a liberdade imanente à sua existência. Segundo Frankl (2005) é necessário que o indivíduo se posicione e responda ao que lhe é apresentado, envolvendo-se nas situações que vivencia. Porém, no contexto atual, o que se manifesta são indivíduos acomodados, que apenas reagem a estímulos ou obedecem aos seus "impulsos". É, definitivamente, uma maneira ilegítima de existir.

A Logoterapia, nesse âmbito, considera imprescindível ao ser humano retomar a consciência de ser-responsável, colocando-a como característica vital para a sua existência. (FRANKL, 1986) Essa conscientização, no entanto, só seria possível através da espiritualidade - não a religiosa, mas aquela que, segundo Frankl, seria a quarta dimensão constituinte do humano (FRANKL, 1990), pois, além das dimensões biológica, psicológica e social, partilhada por homens e animais, a dimensão noética (espiritual) é o que particularizaria a existência humana. Portanto, pela dimensão espiritual os indivíduos obedecem a uma vontade de sentido que ultrapassa a satisfação individual para ser auto transcendente, para realizar-se em algo que está fora de si, no mundo, não a si mesmo. (FRANKL, 2013) Pois "se realmente víssemos no prazer todo o sentido da vida, em última análise a vida parecer-nos-ia sem sentido. Se o prazer fosse o sentido da vida, a vida propriamente não teria sentido algum". (FRANKL, 1986, p. 69)

A configuração social hipermoderna, contudo, demonstra que a existência humana se volta cada vez mais para o prazer, para a autorrealização como primazia. $\mathrm{O}$ ser humano tem encontrado no consumo um atalho para se realizar. Porém, o prazer conquistado através das aquisições se esvai rapidamente e o que resta é apenas o vazio existencial, já que autorrealizarse é uma consequência do encontro com um sentido verdadeiro. (FRANKL, 2013)

Frankl (2013) denominou de "vácuo existencial" o sentimento de vazio advindo das inúmeras queixas que chegavam ao seu consultório. Mais que isso, considerou duas possibilidades de explicar a etiologia do problema: o fato de o indivíduo não possuir instinto ou pulsão que lhe ditasse o que deveria fazer; e o fato das convenções, tradições e valores, que poderiam orientá-lo em como agir, estarem desaparecendo com o passar das gerações e, em consequência, "ele mal sabe o que deseja fazer. Nesse estado de coisas, ou ele acaba querendo fazer o que os outros fazem ou termina por fazer o que os outros querem que ele faça. Isto é, ele se torna vítima, respectivamente, ou do conformismo ou do totalitarismo". (FRANKL, 2013, p. 105)

O ser humano, ao se conformar ou simplesmente se submeter às demandas sociais se anula tão enfaticamente quanto imerge num vácuo existencial. (FRANKL, 1984) Para Frankl, o vácuo existencial se tornou a neurose de massa da atualidade, uma neurose coletiva, caracterizada pelo nulismo, que envolve: uma atitude provisória, de não ter decisão fixa; uma postura fatalista, por acreditar que não há o que fazer para modificar a realidade (atitude passiva); o pensamento coletivista, por não exercer a individualidade de pensar, agindo em consonância com a massa; e o fanatismo, por ter suas opiniões, crenças e pensamentos engessados e não estar aberto a mudanças. (FRANKL, 1984; SILVEIRA e GRADIM, 2015)

Entretanto, os sintomas da neurose coletiva podem se resumir à esquiva da prática da responsabilidade e ao medo de vivenciar a liberdade. (SILVEIRA e GRADIM, 2015)O sentimento de falta de sentido (vácuo existencial) também não se caracterizaria, propriamente, como patologia, mas como algo tipicamente humano (sadio), ainda mais quando se leva em consideração a postura de reconhecimento diante do vazio, configurando-se como uma "expressão de maturidade espiritual".

Frankl enfatiza, no entanto, que o posicionamento ante ao vácuo existencial pode também originar uma resposta patológica, se expressando, da mesma forma que o reconhecimento do vazio, como reação particularmente humana. (SILVEIRA e GRADIM, 2015) Assim, por considerar a singularidade humana, é possível entender que "só ao homem é dado ter a vivência da sua existência como algo problemático; só ele é capaz de experimentar a problematicidade do ser". (FRANKL, 1986, p. 56)

À expressão patológica da frustração existencial, Frankl denominou Neurose Noogênica, por ter origem na dimensão noética (espiritual) do homem e se dar a partir de problemas existenciais (ROEHE, 2005). O convívio com a sensação de vazio existencial por tempo prolongado, assim como conflitos de valores, o ceticismo quanto a um sentido da vida ou a incapacidade em alcança-lo, seriam os aspectos principais da configuração dessa neurose. (KROEFF, 2011) Frankl destaca que nem toda neurose é de ordem noogênica, pois pode se dar a partir das outras dimensões que organizam o indivíduo. Dessa forma, existiriam também neuroses sociogênicas, psicogênicas e, mesmo, iatrogênicas, "isto é, uma neurose causada pelo psicoterapeuta que pretende curá- 
la". (FRANKL, 2013, p. 111)

Sobre a neurose sociogênica pode-se atribuir, juntamente com o sentimento da falta de sentido, o de futilidade e absurdo diante da vida que, com seus principais sintomas, constituiriam a chamada "tríade da neurose de massa", formada pela depressão, a agressão e toxicodependência. (FRANKL, 1990) A sintomatologia da neurose coletiva, porém, pode se repetir ou modificar-se de acordo com a época, pois é provocada pelos apelos hodiernos, em um contexto em que "a sociedade industrial tem em vista diretamente satisfazer, se possível, a todas as necessidades humanas, e seu efeito colateral, a sociedade de consumo, busca até mesmo gerar necessidades, para poder, em seguida, satisfazê-las." (FRANKL, 2014, p. 283)

É válido ressaltar, ademais, as características da tríade primeira estabelecida por Frankl, pois trata de patologias derivadas da ausência de sentido, e que muito se adequa a realidade atual. Sobre a depressão, Frankl (1990) enfatiza que a sua manifestação extrema, o suicídio, tem como principal motivação exatamente a sensação de falta de sentido. O mesmo ocorreria com a agressão e a toxicodependência, que se iniciariam, principalmente, partindo do pressuposto de que quanto maior for o sentimento de falta de sentido, maior a predisposição ao comportamento agressivo ou voltado à dependência de álcool e/ou outras drogas.

Tais características reforçam a continuidade e a persistência dessas patologias e do vazio existencial no indivíduo na sociedade hipermoderna. A neurose coletiva contemporânea se daria na sequência de "faltas" de sentido que foram assolando os sujeitos com o passar do tempo e se concretiza na prática veemente da sociedade - o hiperconsumo -, que não preenche o vazio existencial e a falta de sentido na vida. (FRANKL, 1991)

Sendo a vontade de sentido o motor da existência humana, o prazer nas aquisições estaria voltado para algo primitivo no indivíduo, um atalho para se chegar ao sentido genuíno, maquiado pelas falsas ofertas de felicidade. $\mathrm{O}$ atalho da aquisição é, ao mesmo tempo, uma barreira para a realização desse sentido e o leva à frustração existencial, sentimento derivado da privação de sentido. (FRANKL, 1991)

Nessa perspectiva, a existência saudável, segundo a Logoterapia, se daria pelo redirecionamento da intenção do indivíduo, que se distancia da autorrealização e das determinações sociais de felicidade e prazer, para voltar-se para algo que não seja ele mesmo, "criando um trabalho ou praticando um ato; experimentando algo ou encontrando alguém; pela atitude que tomamos em relação ao sofrimento inevitável" (FRANKL, 1984, p. 51), por exemplo, e, assim, auto transcendendo. "A essência da existência humana, diria eu, radica na sua auto-transcendência. Ser homem significa dirigir-se e ordenar-se a algo ou alguém: entregar-se o homem a uma obra a que se dedica, a um homem quem ama, ou a Deus, a quem serve." (FRANKL, 1986, p. 45)

A Logoterapia como psicoterapia, especificamente, contribui para uma existência saudável dos pacientes quando se direciona ao reconhecimento da responsabilidade concernente a cada um, permitindo que eles próprios seposicionem diante do sintoma/sofrimento em questão e tomem decisões (SILVEIRA e GRADIM, 2015). Desse modo, "o papel do logoterapeuta consiste em ampliar e alargar o campo visual do paciente de forma que todo o espectro do significado e dos valores se torne consciente e visível para ele" (FRANKL, 1977, p. 173-174). "[...] a logoterapia procura direcionar e orientar o paciente para um sentido concreto e pessoal", para torná-lo "[...] capaz de descobrir o sentido da existência, de ampliarmos, por assim dizer, o seu campo de visão, de forma que ele perceba o espectro completo de possibilidades de sentido e de valores pessoais e concretos." (FRANKL, 1991, p. 72)

A finalidade da logoterapia "é incluir o logos na psicoterapia" (FRANKL, 1978, p. 197), ou seja, incluir uma reflexão acerca da própria existência, conduzindo o paciente a ponderar as escolhas feitas frente à responsabilidade e a liberdade, a pensar sobre os sentidos e valores que norteiam a sua vida. "A responsabilidade do homem, conscientizada, assim, pela análise da existência, é uma responsabilidade em vista da irrepetibilidade e do referido 'caráter de algo único' da sua existência" (FRANKL, 1986, p. 118), tendo em vista que "o seu destino não se repete. Ninguém tem as mesmas possibilidades que ele, nem ele próprio as volta a ter" (FRANKL, 1986, p. 120), e nisto singulariza-se.

A responsabilidade, no entanto, só se faz pela liberdade, pois só se é ser-responsável, porque, primeiramente, se é ser-livre. Diante da liberdade, pode ser definido como o ser que se desprende, que se liberta aos poucos do que o determina, "(enquanto tipo determinado biologicamente, psicologicamente e socialmente); quer dizer, como o ser que transcende todas as determinações, denominando-as ou configurando-as" (FRANKL, 1986, p. 121), mas que depende de alguma forma delas.

Ao remeter a responsabilidade e a liberdade humana ao cenário hipermoderno, verificamos que o indivíduo, ao se encontrar imerso na "massa", perde a peculiaridade e a singularidade de ser-responsável. Da mesma forma, quando se esquiva da inevitabilidade das escolhas frente às possibilidades, acaba por agir "“como se' não tivesse nenhuma escolha e nenhuma liberdade de decidir. Mas isto de 'fazer como se' constitui boa parte da tragicomédia do homem" (FRANKL, 1986, p. 122), pois se anula e despersonaliza-se continuamente.

As manifestações dessa anulação existencial se apresentam tanto na negação da liberdade e da responsabilidade - que já se caracteriza como uma falta de motivação primeira e fundamental de encontrar 
sentido para a vida -, como também pode apresentarse diretamente numa forma apática de viver, que não encontra sentido em sua existência. (KROEFF, 2011)

A logoterapia, então, pretende clarificar o olhar do paciente aos sentidos possíveis que se manifestam em suas vivências, que muitas vezes passam despercebidos. Visa conscientizá-lo sobre a sua liberdade, pois é a partir dela que se pode vislumbrar o "vir a ser" - o que pode se tornar - e a imensa gama de possibilidades que poderão ou não ser concretizadas. Tem a intensão de conscientiza-lo totalmente sobre sua responsabilidade diante da vida, até mesmo quando decide não a exercer. (KROEFF, 2011)

Tratando-se das neuroses e das intervenções cabíveis, Frankl enfatiza a necessidade de se identificar a dimensão afetada, para direcionar a psicoterapia mais adequada. E ao constituir-se de uma dimensão espiritual, somente pela logoterapia haveria tratamento para o indivíduo, já que outras psicoterapias desconsideram tal dimensão; assim, para as neuroses noogênicas, advindas dessa dimensão, a logoterapia seria concebida como específica. (KROEFF, 2011)

Enfim, como na sociedade hipermoderna a questão da falta de sentido tem tomado proporções devastadoras, não há dúvidas da enorme contribuição que a logoterapia tem a oferecer para uma existência saudável, ainda mais quando o prazer e a felicidade se tornaram primários e o significado (o sentido), secundário, embora devesse ser protagonista e direcionador da existência. A maior consequência disso, o vácuo existencial, "não só está crescendo, como também se espalhando" (FRANKL, 2013, p. 106), o que evidencia ainda mais o clamor por sentindo.

\section{Considerações finais}

A sociedade hipermoderna tem sido vista como o cenário ideal para o encontro com o vazio. A influência central dessa sociedade, o hiperconsumismo, tem devastado a subjetividade dos indivíduos, levandoos a uma existência irresponsável e aprisionada pelo modo de pensar da coletividade. Mais do que o nulismo existencial, o ser humano tem deixado de vivenciar as suas escolhas de modo singular, pois the são apresentadas "receitas prontas" de aceitação, de pertencimento, de felicidade e prazer, que ele reproduz cegamente, levando-o à falta de sentido.

Sob o olhar da logoterapia, foi possível encontrar um significado mais amplo da questão da busca do prazer e da felicidade, enfatizando que essa busca não pode ser o objetivo de uma satisfação particular, mas, primeiramente, uma doação de si ao outro, ao mundo, para então se efetivar na existência. Da mesma forma, prazer e felicidade não podem ser perseguidos, pois são consequências do encontro primeiro do indivíduo com um sentido para a sua vida. E considerandose as repercussões do seu comportamento irrefletido frente à realidade consumista e o seu resultado - a neurose de massa da atualidade (o vácuo existencial) -, a logoterapia apresenta possibilidades de se alcançar uma existência saudável nessa sociedade, a despeito de tamanha interferência.

Dessa forma, incluir o logos (sentido) em psicoterapia é um modo de incluir a reflexão sobre a existência, colocar em evidência os "porquês", permitindo a ponderação dos sentidos investidos nas ações - daí partiria a volição do exercício da liberdade e da responsabilidade frente às escolhas. Além disso, a logoterapia mostra-se específica para os casos de neurose noogênica (de origem espiritual), resultante da expressão patológica da frustração existencial, que ocorre quando a sensação de vazio existencial se prolonga a ponto de as motivações para viver quase desaparecerem e as aquisições não serem mais capazes de satisfazer, mesmo que momentaneamente.

Nesse cenário, o ser humano necessita, antes de tudo, buscar um sentido para viver. De acordo com a logoterapia, isso ocorre quando o desejo de autorrealização é deixado de lado e o ser humano se destina a satisfazer-se no atendimento da carência do outro, não da sua própria. Além disso, o ser humano precisa posicionar-se frente às ofertas da sociedade, escolhendo, exercendo a sua liberdade e refletindo sobre as escolhas, agindo com responsabilidade para que a felicidade e todo tipo de prazer sejam atingidos como efeito de uma vida em que há sentido.

\section{Referências bibliográficas}

BAUDRILLARD, J. A sociedade de consumo. Lisboa: Ed.70, 1991.

. O sistema dos objetos. São Paulo: Perspectiva, 1993.

BAUMAN, Z. A arte da vida. Rio de Janeiro: Zahar, 2009.

CAMPBELL, C. A ética romântica e o espírito do consumismo moderno. Rio de Janeiro: Rocco, 2001.

FRANKL, V. E. A presença ignorada de Deus. 13. ed. Petrópolis: Sinodal 2011.

A questão do sentido em psicoterapia. Campinas. São Paulo: Papirus, 1990.

A vontade de sentido: fundamentos e aplicações da logoterapia. 2. ed. São Paulo: Paulus, 2013.

Em busca de sentido: um psicólogo no campo de concentração. Prefácio Edição da Norte-Americana, 1984. Porto Alegre: Salinas, 1987.

Fundamentos antropológicos da psicoterapia. Rio de Janeiro: Zahar, 1978.

Logoterapia e análise existencial: textos de seis décadas. Rio de Janeiro: Forense Universitária, 2014.

Man's search for meaning. New York: Poket Books, 
1986

Psicoterapia e sentido da vida. 2. ed. São Paulo: Quadrante,

Psicoterapia na prática. Campinas: Papirus, 1991.

The will to meaning. New York: Meridian Books, 1988.

Um sentido para a vida: psicoterapia e humanismo. 11. ed. São Paulo: Ideias \& Letras, 2005.

HOMERO. Odisseia. São Paulo: Martin Claret, 2002. Col. A obra prima de cada autor - Série de ouro 15

KROEFF, P. Logoterapia: uma visão de psicoterapia. Revista da abordagem gestáltica, v. 17, n. 1, p. 68-74, 2011.

LAZZARI JUNIOR, J. C. Psicologia e religião em Viktor Frankl: a relação entre ciência e espiritualidade na logoterapia. Revista Eletrônica Espaço Teológico, v. 7, n. 11, p. 60-75, jan/jun, 2013.

LIPOVETSKY, G. A felicidade paradoxal. Ensaio sobre a sociedade de hiperconsumo. São Paulo: Companhia das Letras, 2007.

LUKAS, E. Logoterapia: a força desafiadora do espírito. São Paulo: Edições Loyola, 1989.

MATOS, D. C. Felicidade e sentido de vida na sociedade de consumo. Revista Logos \& Existência: revista da associação brasileira de logoterapia e análise existencial, 1 (1), p. 72-78, 2012.

MOREIRA, N.; HOLANDA, A. Logoterapia e o sentido do sofrimento: convergências nas dimensões espiritual e religiosa. Psico, v. 15, n. 3, p. 345-356, set/dez, 2010.

PEREIRA, I. S. A vontade de sentido na obra de Viktor Frankl. Psicologia USP, v. 18, n. 1, p. 125-136, 2007.

RODRIGUES, R. Fundamentos da logoterapia: na clínica psiquiátrica e psicoterapêutica. Rio de Janeiro: Petrópolis, Vozes, v. 1,1991

ROEHE, M. V. Revendo ideias de Viktor Frankl no centenário de seu nascimento. Psico, v. 36, n. 3, p. 311-314, set./dez. 2005.

SILVA, L. B. Sobre o consumo e o consumismo: a consumação do vazio. Revista Logos \& Existência: revista da associação brasileira de logoterapia e análise existencial, 1 (1), p. 79-87, 2012.

SILVEIRA, D. R.; GRADIM, F. J. Contribuições de Viktor Frank1 ao movimento de saúde coletiva. Revista de abordagem gestáltica - Phenomenological Studies, XXI (2), p. 153-161, jul-dez, 2015.

SOUZA, M. A. A sociedade do consumo e a vida do espírito. Ecodebate - Revista cidadania e meio ambiente, n.1, p. 1-7, novembro 2011

ZAMULAK, J. Autotranscendência: caminho para a superação do individualismo. Revista Logos \& Existência: revista da associação brasileira de logoterapia e análise existencial, 4 (2), p. 130-142, 2015. 